\title{
Parameters Estimation and Stability Analysis of Nonlinear Fractional-Order Economic System Based on Empirical Data
}

\author{
Lei He and Xiong Wang \\ School of Business, Central South University, Changsha, Hunan 410083, China \\ Correspondence should be addressed to Xiong Wang; wx2011@csu.edu.cn
}

Received 23 February 2014; Accepted 9 April 2014; Published 30 April 2014

Academic Editor: Fenghua Wen

Copyright ( 2014 L. He and X. Wang. This is an open access article distributed under the Creative Commons Attribution License, which permits unrestricted use, distribution, and reproduction in any medium, provided the original work is properly cited.

\begin{abstract}
This paper is devoted to propose a novel method for studying the macroeconomic system with fractional derivative, which can depict the memory property of actual data of economic variables. First of all, we construct a constrained optimal problem to evaluate the coefficients of nonlinear fractional financial system based on empirical data and design the corresponding genetic algorithm. Then, based on the stability criteria of fractional dynamical systems, the methodology of stability analysis is proposed to investigate the stability of the estimated nonlinear fractional dynamic system. Finally, our method is applied to discuss the macroeconomic system of the US, Australia, and UK to demonstrate its effectiveness and applicability.
\end{abstract}

\section{Introduction}

In a market economy, the macroeconomic stability is an important economic problem which is concerned by all of governments. Macroeconomic instability can take the form of volatility of key macroeconomic variables or of unsustainability in their behavior. Macroeconomic instability refers to phenomena that decrease the predictability of the domestic macroeconomic environment and it is of concern because unpredictability hampers resource-allocation decisions, investment, and growth. Therefore, the analysis of the macroeconomic stability contributes to the making of economic policy decision for governments and controls the macroeconomic instability to improve the predictability.

According to macroeconomic theory, the stability of macroeconomy is measured by the volatility of some key indicators such as consumer price inflation, real GDP growth over business cycles, changes in unemployment, fluctuations in the current of the balance of payments, and volatility of short term policy interest rates and long term interest rates. The existing researches about the stability of macroeconomy concentrate mainly on two directions.

On the one hand, some studies examine the macroeconomic stability by empirical analysis based on the actual data and econometric models and usually include a few macroeconomic indicators, for example, [1-3]. More precisely, the macroeconomic stability and the properties of the international transmission of business cycles under three exchange rate systems are examined by [1]. In [2], whether monetary policy may have been a source of macroeconomic instability in the 1970s by inducing unstable learning dynamics is investigated. In [3], a conventional New Keynesian model for four countries is used to analyze relationship between monetary policy and macroeconomic stability. Empirical analysis of economic stability obtains scientific conclusion based on actual economic data but pays more attention on the factors which affect the volatility of some key indicators and neglects the stability characteristic which implicit in economic dynamic behavior economic system.

On the other hand, some researches build the simplified economic system model according to economic theory and analyze the stability of economic system based on dynamic economics, for example, [4-6]. What is more, Hopf bifurcation theorem is used to predict the occurrence of a limit cycle bifurcation for the time delay parameter of a new IS-LM business cycle model in [7]. Reference [8] studies the implication of imperfect financial contracting for macroeconomic stability in the context of a stochastic 
dynamic general equilibrium model. Reference [9] examines the two most attractive characteristics, memory, and chaos in simulations of fractional financial model. Reference [10] investigates the stability criteria of the bifurcation periodic solutions and then the stability of a business cycle model with discrete delay. Reference [11] analyzes the relationship between interest-rate feedback rules and macroeconomic stability in presence of transaction cost. This method of stability analysis for economic system focuses on dynamic behavior of system evolution, and theory about system stability from dynamic economics is applied extensively in it. However, the considered economic systems are simplified model according to economic theory and neglect the rule of different real economic operation. Thus, there may be some bias between conclusion from it and actual economic situation.

It is well known that the prerequisite for stability analysis of economic system is to construct the reasonable economic model. As an excellent methodology of modeling, fractional calculus is verified to be a powerful tool in modeling most physical processes with memory effect, which cannot be described well by integer-order integral and differential equations (see [12]). With the fractional derivative being applied in economic or financial system, fractional economic models spring up in recent years. For instance, reference [9] proposes the fractional financial system which involves the macroeconomic variables such as investment, interest, and price index. In [13], a delayed fractional-order financial system is proposed. These models are simplified from economic theory. Reference [14] presents macroeconomic modeling based on fractional calculus, but nonlinear structures have not been considered.

The motivation of this paper is to present a new method to model and analyze macroeconomic system based on theory about nonlinear fractional-order system, and this method possesses the merits of the empirical analysis and dynamics economics mentioned above. More precisely, the aim of this paper is to achieve the following: on the one hand, it proposes the method to construct the fractionalorder nonlinear dynamic system which can describe the actual economic data accurately and reveal the rule of operation about real economic system; on the other hand, it introduces stability analysis of fractional-order economic system to investigate the stability of real economic system and proposes a novel method of stability analysis for economic system. In the paper, we will try to design an approach to estimate fractional-order nonlinear economic system based on empirical data and then analyze the stability of estimated system using the stability criteria of fractional-order system.

The remainder of this paper is organized as follows. In Section 2, we review the mathematical preliminaries about fractional calculus and stability of system. In Section 3, we propose a novel methodology to model a nonlinear fractional-order economic system based on nonlinear equation. In Section 4, GA have been used to estimate the macroeconomic system by US, Australia, and UK macroeconomic data. In Section 5, the analysis of dynamic behavior and stability about the macroeconomic system is performed. The conclusions will be shown in Section 6 .

\section{Mathematical Preliminaries}

2.1. Definition of Fractional Calculus. In this section, we introduce some preliminaries of fractional calculus. More properties of fractional derivatives could be found in many books and recent papers; for example, see $[15,16]$.

There exist three most frequently used definitions for the general fractional differintegral which are GrünwaldLetnikov (GL) definition, the Riemann-Liouville (RL), and Caputo definitions. For the GL definition of fractional derivative being convenient to compute numerically, it is applied to solve the fractional-order system in this paper.

Definition 1 (see [17]). The GL definition can be written as

$$
{ }_{a}^{\mathrm{GL}} D_{t}^{\alpha} f(t) \approx h^{-\alpha} \sum_{i=0}^{[(t-a) / h]}(-1)^{k}\left(\begin{array}{l}
\alpha \\
k
\end{array}\right) f\left(t_{k}-i h\right),
$$

where $[x]$ means the integer part of $x$.

2.2. Fractional-Order System. In [18], the general form of $n$ dimensional fractional-order system can be expressed as

$$
\begin{aligned}
{ }_{0} D_{t}^{\alpha_{i}} x_{i}(t) & =f_{i}\left(x_{1}(t), x_{2}(t), \ldots, x_{n}(t), t\right) \\
x_{i}(0) & =c_{i}, \quad i=1,2, \ldots, n,
\end{aligned}
$$

where $c_{i}$ are initial conditions. If $\alpha_{1}=\alpha_{2}=\cdots=\alpha_{n}$, then the system is a commensurate fractional-order system otherwise is called as an incommensurate system. If $f_{i}$ is nonlinear function, the system is a nonlinear system.

2.3. Stability of Fractional-Order System. The exponential stability cannot be used to characterize the asymptotic stability of fractional-order system. A new definition was introduced in [18].

Definition 2 (see [18]). The trajectory $x(t)=0$ of the system (2) is $t^{-q}$ asymptotically stable if there is a positive real $q$ such that for all $\|x(t)\|$ with $t \leq t_{0}, \exists N(x(t))$, such that for all $t \geq$ $t_{0},\|x(t)\| \leq N t^{-q}$.

The fact that the components of $x(t)$ slowly decay towards 0 following $t^{-q}$ leads to fractional systems being called long memory systems. The stability theorem in [19] presents that equilibrium points are asymptotically stable for $\alpha_{1}=\alpha_{2}=$ $\cdots=\alpha_{n}=\alpha$ if all the eigenvalues $\lambda_{i}(i=1,2, \ldots, n)$ of the Jacobian matrix $\mathbf{J}=\partial \mathbf{f} / \partial \mathbf{x}$, where $\mathbf{f}=\left[f_{1}, f_{2}, \ldots, f_{n}\right]^{T}$, evaluated at the equilibrium point, satisfy the condition ([18]):

$$
|\arg (\operatorname{eig}(J))|=\left|\arg \left(\lambda_{i}\right)\right|>\alpha \frac{\pi}{2}, \quad i=1,2, \ldots, n .
$$

For the incommensurate fractional-order system $\alpha_{1} \neq \alpha_{2} \neq \cdots \neq \alpha_{n}$, suppose the $\alpha_{i}$ is the rational number, which $m$ is the LCM (least common multiple) of the denominators $u_{i}$ of $\alpha_{i}$ 's, where $\alpha_{i}=v_{i} / u_{i}, v_{i} \cdot u_{i} \in Z^{+}$for $i=1,2, \ldots, n$, and set $\gamma=1 / m$. According to [18], the incommensurate fractional-order system is asymptotically stable if

$$
|\arg (\lambda)|>\gamma \frac{\pi}{2}
$$


for all roots $\lambda$ of the following equation ([18]):

$$
\operatorname{det}\left(\operatorname{diag}\left(\left[\lambda^{m q_{1}} \lambda^{m q_{2}} \ldots \lambda^{m q_{1}}\right]\right)-\mathbf{J}\right)=0 .
$$

For fractional-order system (2), the necessary stability condition for it to remain chaotic is keeping at least one eigenvalue $\lambda$ in the unstable region (see [19]). Suppose that the unstable eigenvalues of scroll saddle points are $\lambda_{1,2}=$ $a_{1,2} \pm i b_{1,2}$. The necessary condition to exhibit double-scroll attractor of the system remaining in the unstable region is exhibited in [19]. The condition for commensurate derivatives order is

$$
\alpha>\frac{2}{\pi} \arctan \left(\frac{b_{i}}{a_{i}}\right), \quad i=1,2 .
$$

Thus, the instability measure $\pi / 2 m-\min (|\arg (\lambda)|)$ is negative, and the system cannot be chaotic [19].

\section{Modelling Economic System with Fractional-Order Derivatives}

3.1. Nonlinear Fractional-Order System. There exist several financial models reported in recent years. For instance, the study of investment, interest rate, and price index by using a chaotic fractional Chen system is discussed in [9] as

$$
\begin{aligned}
& D_{t}^{\alpha_{1}} x_{t}=z_{t}+\left(y_{t}-a\right) x_{t}, \\
& D_{t}^{\alpha_{2}} y_{t}=1-b y_{t}-x_{t}^{2}, \\
& D_{t}^{\alpha_{3}} z_{t}=-x_{t}-c z_{t},
\end{aligned}
$$

where $x, y, z$ represent the interest rate, investment, and inflation, respectively. The subscript $t$ indicates that the variable depends on $t$. Parameters $a, b$, and $c$ are nonnegative coefficients with economic interpretation. $\alpha_{i} \in(0,1], i=$ $1,2,3$, represents the fractional order of the derivatives. If $\alpha_{1}=\alpha_{2}=\alpha_{3}=1$, (7) reduces to the integer-order Chen system.

Instead of considering the same expressions in fractional chaotic Chen system, we assume a more general form of nonlinear fractional system as

$$
\begin{aligned}
D_{t}^{\alpha_{1}} x(t)= & c_{1}+a_{11} x(t)+a_{12} y(t)+a_{13} z(t) \\
& +a_{14} x(t) y(t)+a_{15} y(t) z(t)+a_{16} z(t) x(t) \\
& +a_{17} x^{2}(t)+a_{18} y^{2}(t)+a_{19} z^{2}(t), \\
D_{t}^{\alpha_{2}} y(t)= & c_{2}+a_{21} x(t)+a_{22} y(t)+a_{23} z(t) \\
& +a_{24} x(t) y(t)+a_{25} y(t) z(t)+a_{26} z(t) x(t) \\
& +a_{27} x^{2}(t)+a_{28} y^{2}(t)+a_{29} z^{2}(t), \\
D_{t}^{\alpha_{3}} z(t)= & c_{3}+a_{31} x(t)+a_{32} y(t)+a_{33} z(t) \\
& +a_{34} x(t) y(t)+a_{35} y(t) z(t) a_{36} z(t) x(t) \\
& +a_{37} x^{2}(t)+a_{38} y^{2}(t)+a_{39} z^{2}(t),
\end{aligned}
$$

where $x(t), y(t), z(t)$ are the economic variables.
Let

$$
\begin{aligned}
& f_{1}(\left.(t), y(t), z(t), A_{1}\right) \\
&= c_{1}+a_{11} x(t)+a_{12} y(t)+a_{13} z(t) \\
&+a_{14} x(t) y(t)+a_{15} y(t) z(t)+a_{16} z(t) x(t) \\
&+a_{17} x^{2}(t)+a_{18} y^{2}(t)+a_{19} z^{2}(t), \\
& f_{2}\left(x(t), y(t), z(t), A_{2}\right) \\
&=c_{2}+a_{21} x(t)+a_{22} y(t)+a_{23} z(t) \\
& \quad+a_{24} x(t) y(t)+a_{25} y(t) z(t)+a_{26} z(t) x(t) \\
& \quad+a_{27} x^{2}(t)+a_{28} y^{2}(t)+a_{29} z^{2}(t), \\
& f_{3}\left(x(t), y(t), z(t), A_{3}\right) \\
&=c_{3}+a_{31} x(t)+a_{32} y(t)+a_{33} z(t) \\
& \quad+a_{34} x(t) y(t)+a_{35} y(t) z(t)+a_{36} z(t) x(t) \\
& \quad+a_{37} x^{2}(t)+a_{38} y^{2}(t)+a_{39} z^{2}(t), \\
& \quad A_{i}=\left(c_{i}, a_{i 1}, a_{i 2}, \ldots, a_{i 9}\right), \quad i=1,2,3 .
\end{aligned}
$$

Then the model can be rewritten as

$$
\begin{aligned}
& D_{t}^{\alpha_{1}} x(t)=f_{1}\left(x(t), y(t), z(t), A_{1}\right), \\
& D_{t}^{\alpha_{2}} y(t)=f_{2}\left(x(t), y(t), z(t), A_{2}\right), \\
& D_{t}^{\alpha_{3}} z(t)=f_{3}\left(x(t), y(t), z(t), A_{3}\right) .
\end{aligned}
$$

3.2. Fitting of Fractional-Order Nonlinear System. In order to estimate the parameters of the system, the numerical calculation of the fractional-order derivative will be used. According to the GL definition of fractional-order derivative (1), the explicit numerical approximation has the following form ([17]):

$$
{ }_{\left(k-L_{m} / h\right)} D_{t_{k}}^{\alpha} f(t) \approx h^{-\alpha} \sum_{i=0}^{k} c_{i}^{(\alpha)} f\left(t_{k-i}\right),
$$

where $t_{k}=k h, h$ is the time step of discretization, $L_{m}$ is called as "memory length," and $c_{i}^{(\alpha)}(i=0,1, \ldots)$ are binomial coefficients, which can be calculated as

$$
c_{0}^{(\alpha)}=1, \quad c_{i}^{(\alpha)}=\left(1-\frac{1+\alpha}{i}\right) c_{i-1}^{(\alpha)} .
$$


Then, the general numerical solution of the fractional-order system (11) can be expressed as

$$
\begin{aligned}
& x\left(t_{k}\right)=f_{1}\left(x\left(t_{k}\right), y\left(t_{k}\right), z\left(t_{k}\right), A_{1}\right)-\sum_{j=v_{1}}^{k} c_{j}^{\alpha_{1}} x\left(t_{k-j}\right), \\
& y\left(t_{k}\right)=f_{2}\left(x\left(t_{k}\right), y\left(t_{k}\right), z\left(t_{k}\right), A_{2}\right)-\sum_{j=v_{2}}^{k} c_{j}^{\alpha_{2}} y\left(t_{k-j}\right), \\
& z\left(t_{k}\right)=f_{3}\left(x\left(t_{k}\right), y\left(t_{k}\right), z\left(t_{k}\right), A_{3}\right)-\sum_{j=v_{3}}^{k} c_{j}^{\alpha_{3}} z\left(t_{k-j}\right) .
\end{aligned}
$$

The "short memory" principles have been considered in this expression. The lower index of the sums in it will be $v_{i}=1$ for $k<\left(L_{i} / h\right)$ and $v_{i}=k-\left(L_{i} / h\right)$ for $k>\left(L_{i} / h\right)$, or when "short memory" principle is not being considered, we put $v_{i}=1$ for all $k$. Assume that the actual economic data are $(X(i), Y(i), Z(i))(i=1,2, \ldots, n)$. Let $\boldsymbol{\alpha}=\left(\alpha_{1}, \alpha_{2}, \alpha_{3}\right)$, $\mathbf{A}=\left(A_{1}, A_{2}, A_{3}\right)$. In order to ensure that trajectory of the system describes the empirical economic data, we construct constrained optimal problem as follows:

$$
\begin{aligned}
\min H(\boldsymbol{\alpha}, \mathbf{A})= & \sum_{i=1}^{n-1}(x(i)-X(i+1))^{2} \\
& +\sum_{i=1}^{n-1}(y(i)-Y(i+1))^{2} \\
& +\sum_{i=1}^{n-1}(z(i)-Z(i+1))^{2},
\end{aligned}
$$

subject to

$$
\begin{aligned}
x\left(t_{k}\right)= & f_{1}\left(x\left(t_{k}\right), y\left(t_{k}\right), z\left(t_{k}\right), A_{1}\right) \\
& -\sum_{j=1}^{k} c_{j}^{\alpha_{1}} x\left(t_{k-j}\right), \\
y\left(t_{k}\right)= & f_{2}\left(x\left(t_{k}\right), y\left(t_{k}\right), z\left(t_{k}\right), A_{2}\right) \\
& -\sum_{j=1}^{k} c_{j}^{\alpha_{2}} y\left(t_{k-j}\right), \\
z\left(t_{k}\right)= & f_{3}\left(x\left(t_{k}\right), y\left(t_{k}\right), z\left(t_{k}\right), A_{3}\right) \\
& -\sum_{j=1}^{k} c_{j}^{\alpha_{3}} z\left(t_{k-j}\right), \quad 0<\alpha_{i}<2, i=1,2,3,
\end{aligned}
$$

where

$$
x\left(t_{0}\right)=X(1), \quad y\left(t_{0}\right)=Y(1), \quad z\left(t_{0}\right)=Z(1) .
$$

Then, we can estimate the coefficients of fractional-order system (10) by solving the optimal problem (14) when then actual data is known.

Remark 3. About constraints in the optimal problem, $x, y, z$ are obtained by implicit dynamic equations. In the process of solving it, we can calculate it by transferring it to explicit dynamic equations.

\subsection{Optimal Parameters Estimations of Fractional-Order Non-} linear System by GA. In this paper, the optimal problem (14) will be solved by genetic algorithms (GA). The solutions of the optimal problem are optimal parameters of fractionalorder nonlinear system which describe accurately empirical economic data. The genetic algorithm is an example of a search procedure that uses random selection for optimization of a function by means of the parameters space coding. It was developed by [20] and the most popular references are $[21,22]$. The GA have been proven successful for robust searches in complex spaces. [23] states the validity of the technique in applications of optimization and robust search. The GA have been credited as efficient and effective in the approach for the search.

Comparing with usual constrained optimal problem, the difference of constrained optimal problem (14) includes a process of solving fractional-order system in calculating the fitness of each chromosome in population. The genetic algorithms of solving constrained optimal problem (14) can be designed as the following steps.

Step 1. Generate random population of chromosomes $P(0)$ with population size $N$ in feasible region of problem (14) $\left\{(\boldsymbol{\alpha}, \mathbf{A}) \mid \mathbf{A} \in R^{30}, 0<\alpha_{i}<2, i=1,2,3\right\}$. Set $k=0$.

Step 2. Evaluate the fitness of each chromosomes in the population $P(k)$. Set $x\left(t_{0}\right)=X(1), y\left(t_{0}\right)=Y(1), z\left(t_{0}\right)=$ $Z(1), m=n-1$. Given time step $h$, calculate the $\left(x\left(t_{i}\right), y\left(t_{i}\right), z\left(t_{i}\right)\right)(i=1,2, \ldots, m)$ by recursive formula (13) based on parameters $\left(\boldsymbol{\alpha}_{j}, \mathbf{A}_{j}\right)(j=1,2, \ldots, N)$ which are decoded from chromosomes in $P(k)$. Then, compute the finesses of the chromosomes $f_{j}$ by $H\left(\boldsymbol{\alpha}_{j}, \mathbf{A}_{j}\right)(j=$ $1,2, \ldots, N)$.

Step 3. Create a new population $P(k+1)$ by repeating the following steps until the new population is complete.

(a) Select two parent chromosomes from population $P(k)$ according to their fitness. Calculate selected probability of chromosomes in $P(k)$ by $p_{i}=f_{i} / \sum_{i} f_{i}(i=$ $1,2, \ldots, N)$. The parent chromosomes are selected to be the parent by roulette selection operator.

(b) Cross over the parents to form new offspring with crossover probability $p_{c}$.

(c) Mutate new offspring at each locus with a mutation probability $p_{m}$. Place new offspring in the new population. 
Step 4. If stop criterion is satisfied, then stop. Otherwise, replace $P(k)$ by $P(k+1)$, and go to Step 2 .

3.4. Stability Analysis for Nonlinear Fractional-Order System. The stability as an extremely important property of the dynamical systems is investigated in various domains. According to stability criteria in [18], the stability of fractional nonlinear system is investigated by analyzing the characteristic of equilibrium points in system. $\left(x^{*}, y^{*}, z^{*}\right)$ represents an arbitrary equilibrium points of system (10), which is calculated by solving the equations $f_{i}(x(t), y(t), z(t))=$ $0(i=1,2,3)$. The Jacobian matrix is

$$
J=\left(\begin{array}{lll}
j_{11} & j_{12} & j_{13} \\
j_{21} & j_{22} & j_{23} \\
j_{31} & j_{32} & j_{33}
\end{array}\right),
$$

where

$$
\begin{aligned}
& j_{11}=a_{11}+a_{14} x_{2}^{*}+a_{16} x_{3}^{*}+2 a_{17} x_{1}^{*}, \\
& j_{12}=a_{12}+a_{14} x_{1}^{*}+a_{15} x_{1}^{*}+2 a_{18} x_{2}^{*}, \\
& j_{13}=a_{13}+a_{15} x_{1}^{*}+a_{16} x_{2}^{*}+2 a_{19} x_{3}^{*}, \\
& j_{21}=a_{21}+a_{24} x_{2}^{*}+a_{26} x_{3}^{*}+2 a_{27} x_{1}^{*}, \\
& j_{22}=a_{22}+a_{24} x_{1}^{*}+a_{25} x_{1}^{*}+2 a_{28} x_{2}^{*}, \\
& j_{23}=a_{23}+a_{25} x_{1}^{*}+a_{26} x_{2}^{*}+2 a_{29} x_{3}^{*}, \\
& j_{31}=a_{31}+a_{34} x_{2}^{*}+a_{36} x_{3}^{*}+2 a_{37} x_{1}^{*}, \\
& j_{32}=a_{32}+a_{34} x_{1}^{*}+a_{35} x_{1}^{*}+2 a_{38} x_{2}^{*}, \\
& j_{33}=a_{33}+a_{35} x_{1}^{*}+a_{36} x_{2}^{*}+2 a_{39} x_{3}^{*} .
\end{aligned}
$$

Let optimal order in fractional nonlinear system (10) be $\left(\widehat{\alpha}_{1}, \widehat{\alpha}_{2}, \widehat{\alpha}_{3}\right) . \widehat{\alpha}_{i}(i=1,2,3)$ can be expressed $v_{i} / u_{i}(i=$ $1,2,3)$, and $m$ is the LCM (least common multiple) of the denominators $u_{i}(i=1,2,3)$. Let $m_{i}=m \widehat{\alpha}_{i}$. According to (6), the characteristic equation is as follows:

$$
\begin{aligned}
& \lambda^{m_{1}+m_{2}+m_{3}}-j_{22} \lambda^{m_{3}+m_{1}}-j_{33} \lambda^{m_{2}+m_{1}}-j_{11} \lambda^{m_{3}+m_{2}} \\
& +b_{1} \lambda^{m_{1}}+b_{2} \lambda^{m_{2}}+b_{3} \lambda^{m_{3}}+b_{4}=0,
\end{aligned}
$$

where

$$
\begin{aligned}
b_{1}= & j_{22} j_{33}-j_{23} j_{32}, \\
b_{2}= & j_{11} j_{33}-j_{13} j_{31}, \\
b_{3}= & j_{11} j_{22}-j_{12} j_{21}, \\
b_{4}= & -\left(j_{22} j_{33}-j_{23} j_{32}\right) j_{11} \\
& +j_{12}\left(j_{33} j_{21}-j_{23} j_{31}\right)-j_{13}\left(j_{21} j_{32}-j_{31} j_{22}\right) .
\end{aligned}
$$

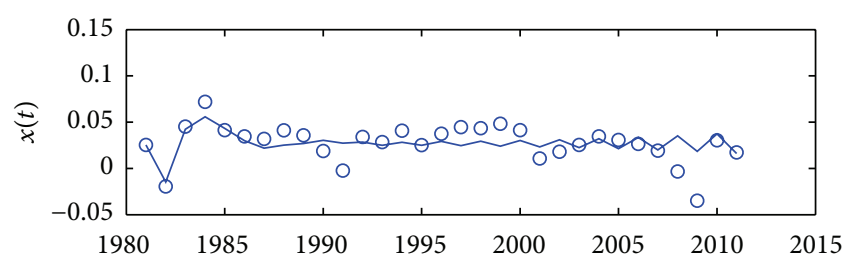

(a)

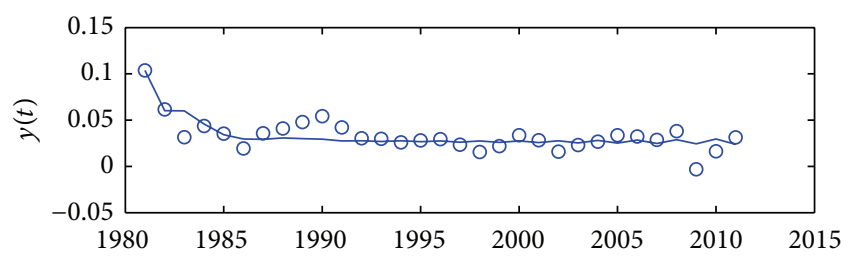

(b)

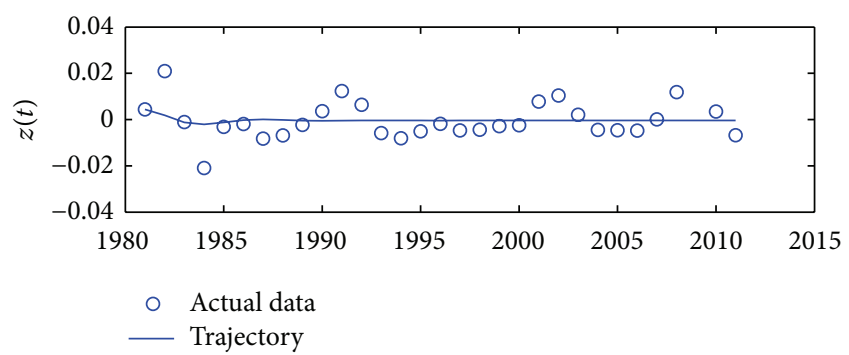

(c)

Figure 1: The actual data versus trajectories of fractional-order system in each dimension about US.

The roots of $(19)$ are $\omega_{i}\left(i=1,2, \ldots, m_{1}+m_{2}+\right.$ $\left.m_{3}\right)$, and the instability measure of equilibrium point is $\pi / 2 m-\min (|\arg (\omega)|)$. If instability measure is negative, the equilibrium point is stable.

\section{Application to Economic System of US, Australia, and UK}

In this section, we will show how to analyze the stability of macroeconomic system based on the actual data by fractional-order system. Firstly, the optimal fractional-order system needs to be estimated based on actual data. This study will take the three nations (i.e., USA, Australia, and UK) for example to show the feasibility and effectiveness of our method.

4.1. Selection of Economic Variables and Data Resource. The GDP, inflation, and unemployment are the key macroeconomic indexes which governments concern. In this paper, the percent change of GDP, average consumer prices percent change rate, and change of unemployment rate percent of total labor force are used to reflect the variables GDP, inflation, and unemployment, respectively. The annual data starts from year 1980 to 2011. The resource of data about percent change of GDP, average consumer prices percent change rate, and unemployment rate percent of total labor force is EconStats which is organized by IMF. Let economic 
TABLE 1: Optimal parameters of fractional order economic system for US, Australia, UK.

\begin{tabular}{|c|c|c|c|c|c|c|c|c|c|}
\hline & \multicolumn{3}{|c|}{ US } & \multicolumn{3}{|c|}{ Australia } & \multicolumn{3}{|c|}{ UK } \\
\hline & $x$ & $y$ & $z$ & $x$ & $y$ & $z$ & $x$ & $y$ & $z$ \\
\hline$\widehat{q}$ & 0.298 & 0.518 & 1.521 & 0.459 & 0.127 & 1.992 & 0.503 & 0.521 & 0.611 \\
\hline$\widehat{c}$ & 0.141 & 0.845 & -42.503 & 0.936 & 0.128 & 0.957 & 1.271 & 1.618 & 0.959 \\
\hline$\widehat{a}_{.1}$ & -7.360 & -26.756 & 19.654 & 9.923 & -2.817 & 3.007 & -10.655 & -70.531 & -13.637 \\
\hline$\widehat{a}_{.2}$ & 10.596 & 42.678 & -45.415 & 2.352 & 2.855 & 2.661 & -85.040 & 54.652 & 19.055 \\
\hline$\widehat{a}_{.3}$ & -208.649 & -82.896 & -3.255 & 1.696 & -4.907 & -1.889 & -91.272 & -73.995 & 100.756 \\
\hline$\widehat{a}_{.4}$ & 106.886 & 134.066 & 7.465 & 1.011 & 2.837 & -1.094 & 37.836 & 98.484 & -31.076 \\
\hline$\widehat{a}_{.5}$ & -92.283 & -29.489 & -9.162 & 6.746 & -13.460 & -0.854 & -28.490 & -60.796 & 17.146 \\
\hline$\widehat{a}_{.6}$ & -46.156 & 0.388 & -9.954 & -10.966 & -8.466 & -6.662 & 0.939 & 37.492 & 2.462 \\
\hline$\widehat{a}_{.7}$ & -40.568 & 24.615 & 33.139 & 1.639 & -9.793 & -1.183 & -31.064 & -46.859 & 2.666 \\
\hline$\widehat{a}_{.8}$ & -28.753 & 98.083 & -19.133 & 0.152 & 14.682 & 2.982 & 65.905 & 28.800 & 32.485 \\
\hline$\widehat{a}_{.9}$ & -17.425 & -18.006 & -19.731 & -4.210 & 0.094 & -1.558 & -18.148 & -34.796 & 3.771 \\
\hline MSE & & $4.8 e-4$ & & & $6.6 e-4$ & & & $5.5 e-4$ & \\
\hline
\end{tabular}

Notes: $\widehat{c}$ denote the $\left(\widehat{c}_{1}, \widehat{c}_{2}, \widehat{c}_{3}\right) . \widehat{a}_{i}$ denote $\left(\widehat{a}_{1 i}, \widehat{a}_{2 i}, \widehat{a}_{3 i}\right)(i=1,2, \ldots, 9)$. MSE is mean of squared error.

TABLE 2: Results about stability analysis of economic system about US.

\begin{tabular}{lcc}
\hline Point & Jacob Matrix & Unstable measure \\
\hline$\left[\begin{array}{l}-5.110 \\
-1.548 \\
7.852\end{array}\right]$ & {$\left[\begin{array}{ccc}70.2 & 2023.7 & -844.3 \\
-106.3 & 1373.3 & 943.5 \\
7.1 & 40.9 & -369.8\end{array}\right]$} & -0.0099 \\
{$\left[\begin{array}{c}0.573 \\
-0.664 \\
-0.450\end{array}\right]$} & {$\left[\begin{array}{ccc}127.316 & -121.140 & 158.997 \\
69.603 & -167.274 & 50.804 \\
-41.309 & -35.030 & -17.834\end{array}\right]$} & \\
{$\left[\begin{array}{c}0.726 \\
-0.976 \\
-1.046\end{array}\right]$} & {$\left[\begin{array}{ccc}233.291 & -191.453 & 238.417 \\
113.160 & -275.220 & -36.399 \\
-34.911 & -62.111 & 8.973\end{array}\right]$} & 0.0314 \\
{$\left[\begin{array}{c}0.756 \\
-0.157 \\
-0.194\end{array}\right]$} & {$\left[\begin{array}{ccc}-18.986 & -173.095 & 117.048 \\
20.167 & -123.163 & 110.606 \\
-53.771 & -1.853 & -30.909\end{array}\right]$} & 0.0314 \\
\hline
\end{tabular}

TABLE 3: Results about stability analysis of economic system about Australia.

\begin{tabular}{lccc}
\hline Point & Jacob Matrix & Unstable measure \\
\hline$\left[\begin{array}{l}-0.246 \\
0.499 \\
0.523\end{array}\right]$ & {$\left[\begin{array}{ccc}8.235 & 12.888 & 5.630 \\
-5.195 & -9.900 & 10.798 \\
-3.710 & 4.080 & 5.623\end{array}\right]$} & 0.0069 \\
{$\left[\begin{array}{l}1.125 \\
0.964 \\
0.509\end{array}\right]$} & {$\left[\begin{array}{ccc}-23.442 & 9.936 & 10.148 \\
-30.502 & -25.774 & 8.018 \\
13.691 & 2.606 & 3.643\end{array}\right]$} & \\
{$\left[\begin{array}{l}-0.053 \\
-0.470 \\
-1.272\end{array}\right]$} & {$\left[\begin{array}{ccc}-4.953 & 7.269 & -1.261 \\
20.453 & 3.040 & -28.320 \\
2.225 & 3.387 & -4.466\end{array}\right]$} & 0.0314 \\
{$\left[\begin{array}{l}-3.948 \\
-2.578 \\
0.352\end{array}\right]$} & {$\left[\begin{array}{ccc}98.290 & 14.679 & -18.923 \\
74.888 & 68.047 & 36.691 \\
-47.077 & 3.980 & 11.281\end{array}\right]$} & \\
\end{tabular}


TABLE 4: Results about stability analysis of economic system about UK.

\begin{tabular}{|c|c|c|c|c|}
\hline Point & \multicolumn{2}{|c|}{ Jacob matrix } & Unstable measure & Stability \\
\hline$[-7.396]$ & 226.2 & $985.8 \quad 190.3$ & & \\
\hline-3.483 & -464 & $1076.5-302.1$ & 0.0157 & Unstable \\
\hline 2.776 & -338.8 & $-863.7 \quad 331.4$ & & \\
\hline$[2.214]$ & {$[-138.774$} & $-278.268 \quad 123.998]$ & & \\
\hline 1.402 & 29.238 & $-309.613 \quad 220.292$ & 0.0157 & Unstable \\
\hline 0.570 & 162.894 & $199.199 \quad-26.786$ & & \\
\hline$[-2.511]$ & {$[-76.666$} & $71.742 \quad-351.173]$ & & \\
\hline 1.331 & -182.166 & $-176.300-371.135$ & -0.0120 & Stable \\
\hline$[-1.694]$ & 93.656 & $-206.896 \quad-28.261$ & & \\
\hline$[0.072]$ & {$[-5.747$} & $-21.294 \quad 7.501]$ & & \\
\hline 0.074 & 0.690 & $-81.415 \quad 58.050$ & -0.0293 & Stable \\
\hline$[0.014$ & 9.010 & $-6.423 \quad-19.114]$ & & \\
\hline$[0.364]$ & {$[-35.584$} & $\left.\begin{array}{ll}-63.879 & 20.743\end{array}\right]$ & & \\
\hline 0.381 & -5.177 & $-123.619 \quad 72.924$ & -0.0249 & Stable \\
\hline$[0.097$ & 42.803 & $22.055 \quad-17.532$ & & \\
\hline$[-4.748]$ & 467.206 & $400.040 \quad-876.792]$ & & \\
\hline-3.316 & 258.412 & $-3.671 \quad-559.485$ & 0.0157 & Unstable \\
\hline-6.044 & -460.158 & $-321.884 \quad-321.041$ & & \\
\hline
\end{tabular}

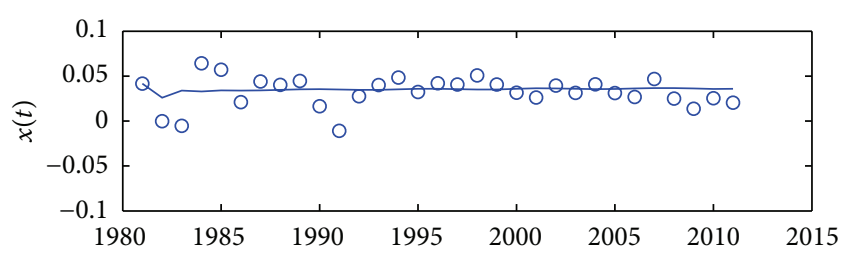

(a)

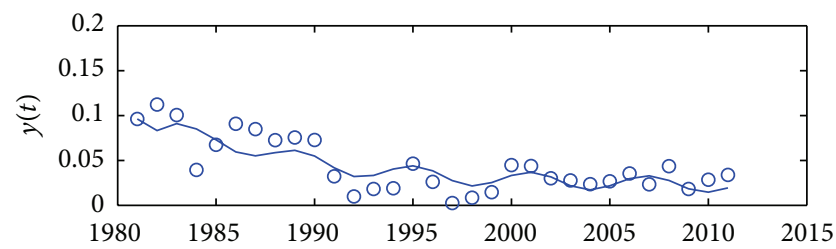

(b)

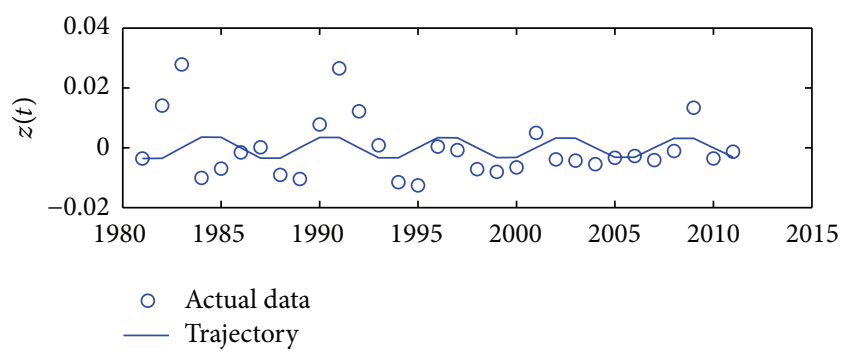

(c)

FIgURE 2: The actual data versus trajectories of fractional-order system in each dimension about Australia.

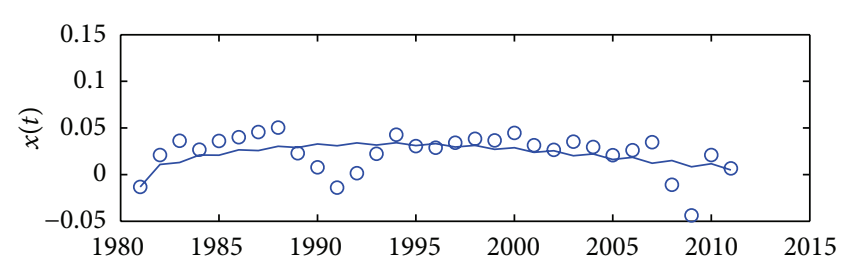

(a)

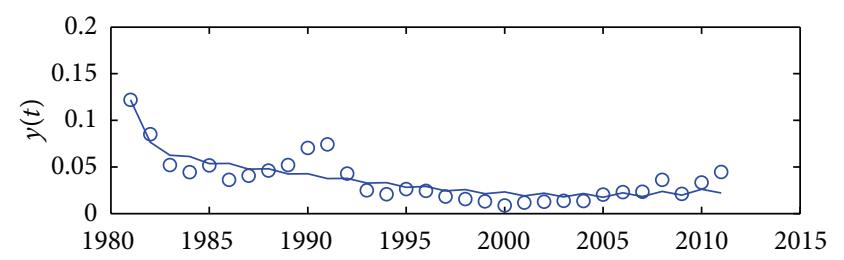

(b)

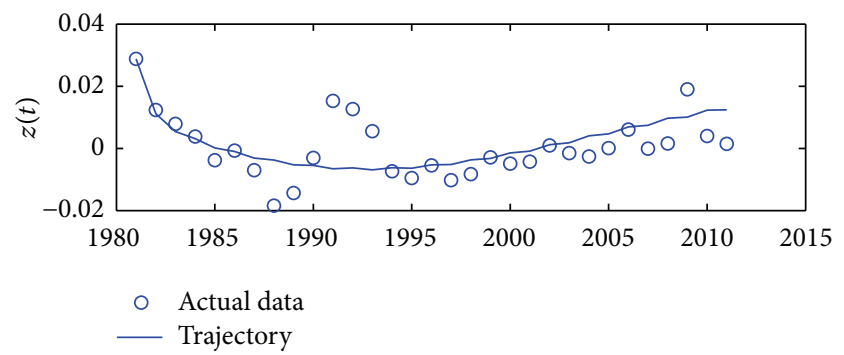

(c)

FIgURE 3: The actual data versus trajectories of fractional-order system in each dimension about UK. 


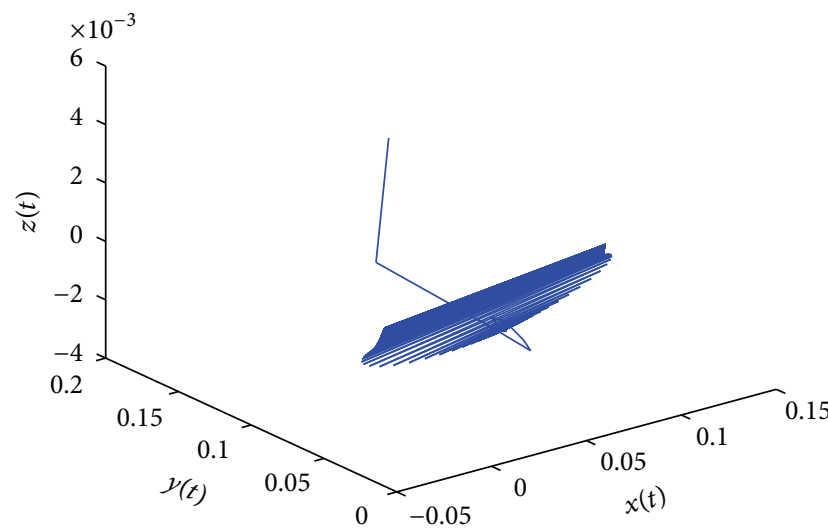

(a) Space trajectories

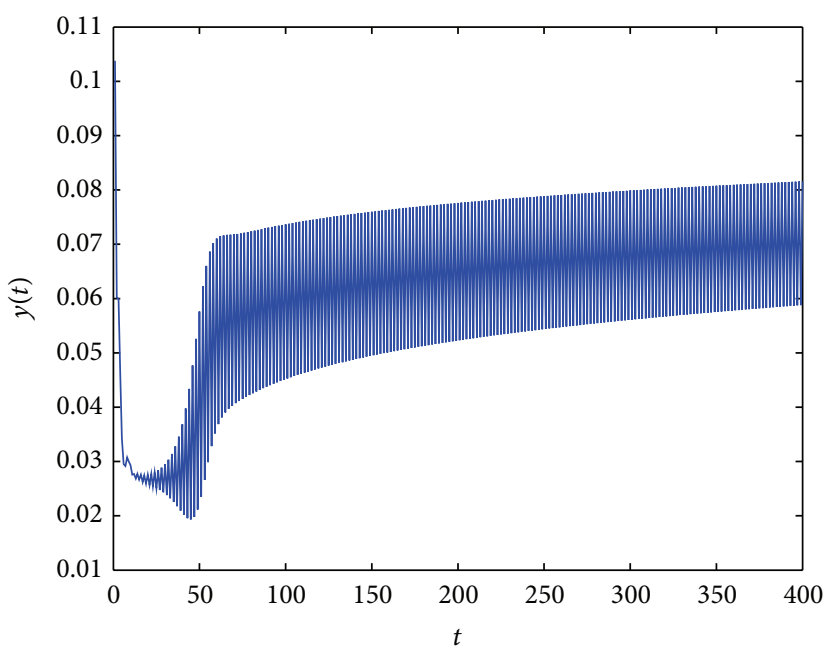

(c) $y(t)$ versus time

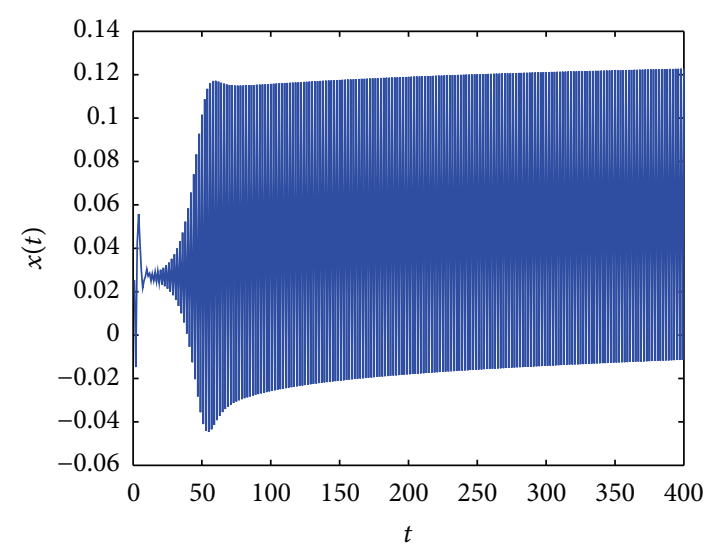

(b) $x(t)$ versus time

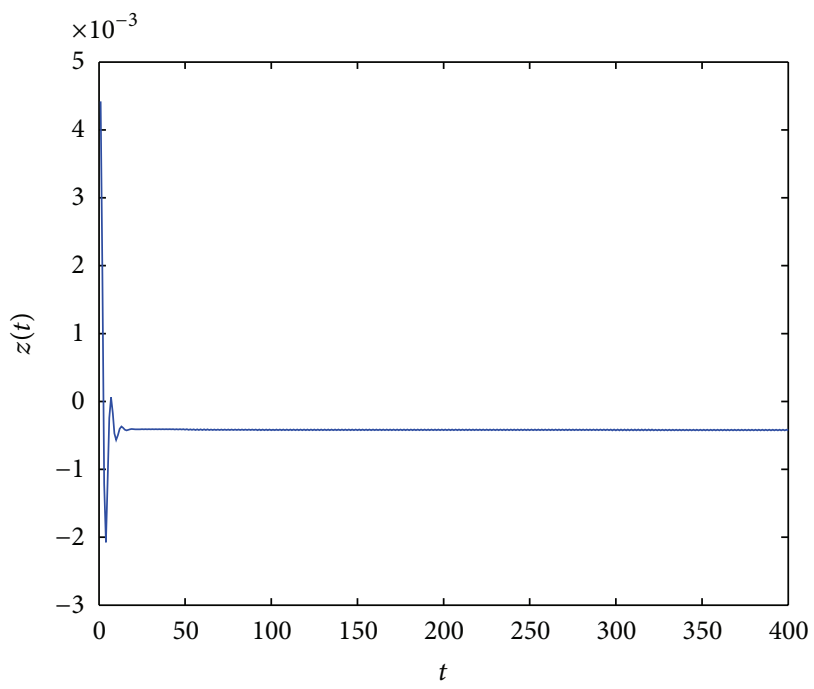

(d) $z(t)$ versus time

variables $x(t), y(t), z(t)$ in (13) be the percent change of GDP, average consumer prices percent change rate, and change of unemployment rate, respectively.

Remark 4. The difference of series may alter the some characteristic of 12 it (such as stationary of series). In order to be consistent with the percent change of GDP, average consumer prices percent change rate, this paper will select change of unemployment rate to be variable which reflects the unemployment of a nation.

4.2. Estimation of Fractional-Order Nonlinear System Based on Genetic Algorithms. This paper adopts the GA to search the optimal parameters of fractional-order system by using the actual data from US, Australia, and UK. Under the time step $h=0.0005$, (13) have been fit by GA, and optimal parameters are shown in Table 1.

In order to show intuitively the accuracy of the optimal system estimated, the comparison of actual data and trajectories of system in each dimension have been shown in
Figures 1-3. From Figure 1, we can find that the accuracy of fit about US economic data is satisfying in economic variables GDP and inflation, and the goodness of fit about unemployment is worse than other variables for which the bias of the last points is obvious. Figure 2 shows the accuracy of fit about Australian economic data in three dimensions. It suggests that the estimated fractional economic system can describe actual data of Australia accurately. Figure 3 shows the goodness of fit about UK data and suggests that trajectory of GDP and inflation are more close to actual data than unemployment.

\section{Stability Analysis of Nonlinear Fractional-Order Macroeconomic System}

In this section, we will analyze the dynamic behavior of the macroeconomic systems with optimal parameters by the simulation technique. The fractional-order economic system estimated by actual economic data from US, Australia, and UK will be analyzed, respectively, as follows. 


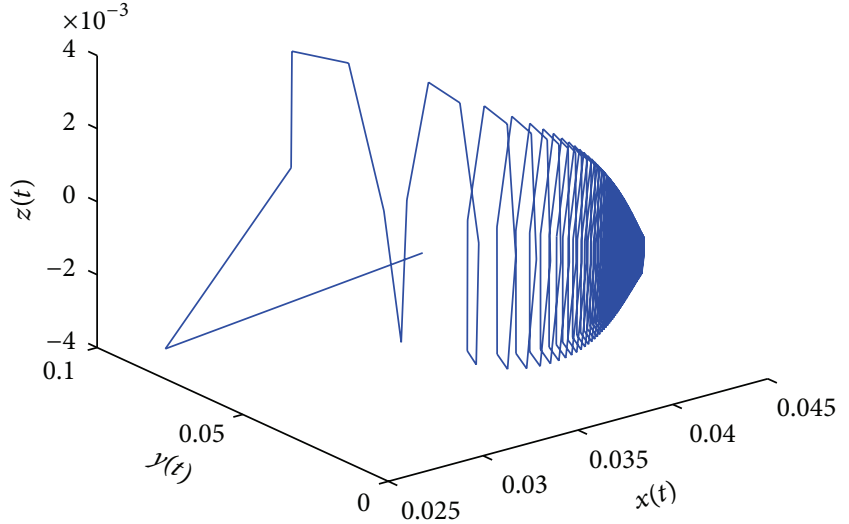

(a) Space trajectories

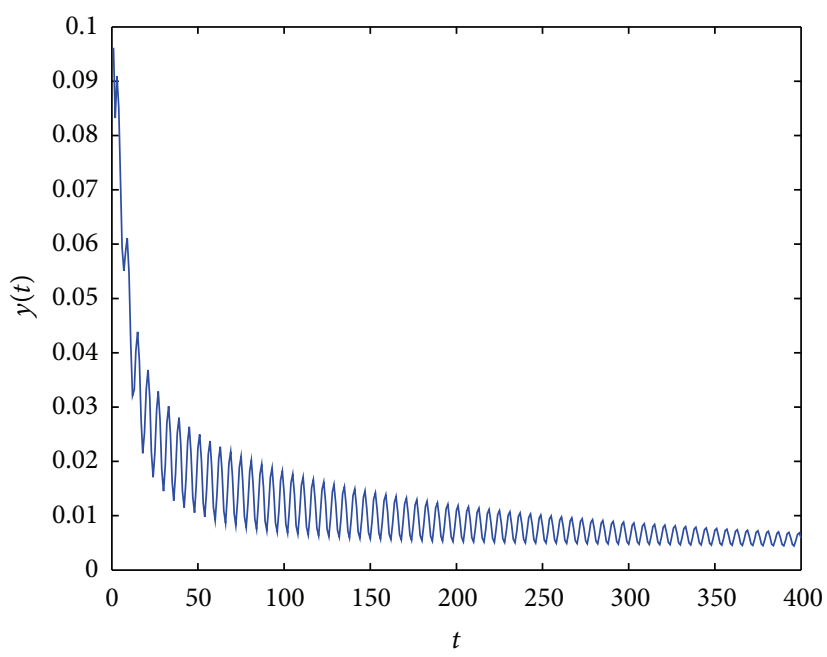

(c) $y(t)$ versus time

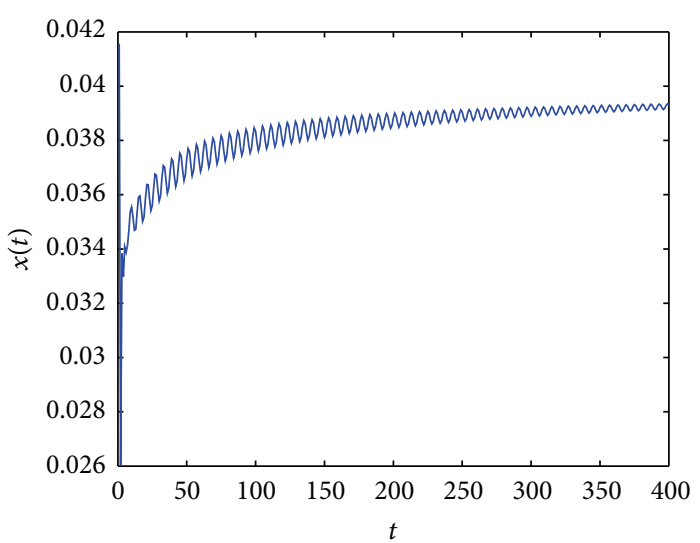

(b) $x(t)$ versus time

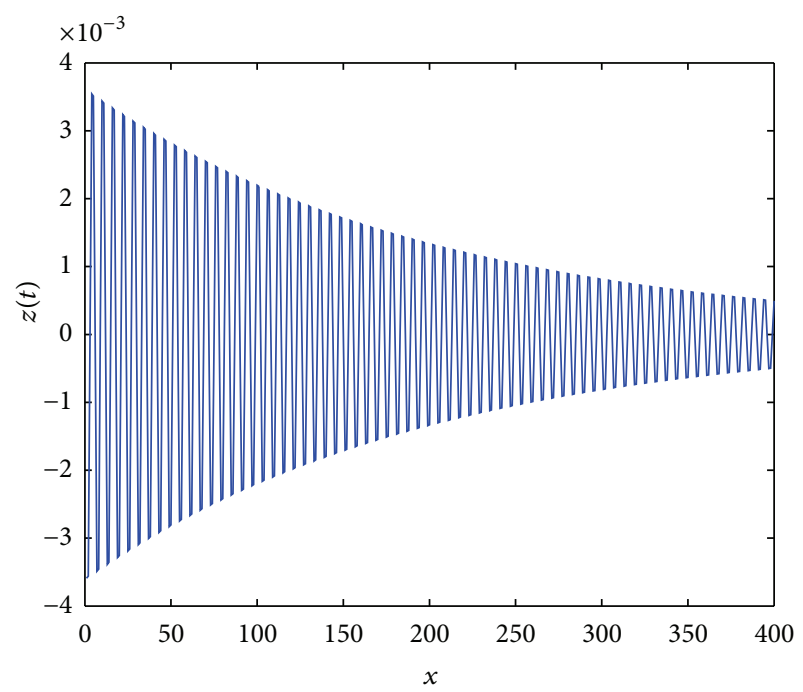

(d) $z(t)$ versus time

FIGURE 5: Space trajectory and the time responses of the estimated system about Australia.

5.1. Fractional-Order Economic System about US. We will analyze the stability of the fractional macroeconomic system for US estimated in Table 1 using the stability criteria in [19]. For number of characteristic root equation (5) depending on the $m$ (LCM of denominates of the fractional order), the optimal order $(0.298,0.518,1.522)$ round to decile $(0.30,0.52,1.52)$ in stability of analysis. Thus, $m=50$ and $\gamma(\pi / 2 m)=0.0314$. The estimated fractional macroeconomic system has four equilibriums at $(-5.110,-1.548,7.852),(0.573,-0.664,-0.450)$, $(0.726,-0.976,-1.046)$, and $(0.756,-0.157,-0.194)$. We will analyze the stability of each equilibrium point.

In Table 2, the results show that there are two unstable equilibrium points and two stable equilibrium points in the fractional-order macroeconomic system about US. These mean that macroeconomic dynamic systems of US have two saddle points and two stable points. The numerical simulation about fractional economic system is shown in Figure 4. From simulation results about trajectory and time responses of each variable in Figure 4, the variables GDP and inflation fluctuate periodically and change of unemployment becomes a constant after a given time. This suggests that economic system of US tends to be stable with time changing, and there is nonchaotic behavior in fractional system about US.

5.2. Fractional-Order Economic System about Australia. In Table 1, the optimal order of fractional-order economic system about Australia is $(0.459,0.127,1.991)$ and round to decile $(0.46,0.13,1.99)$ to control the number of characteristic root. Obviously, $m=100$; then $\gamma(\pi / 2 m)=0.0157$. The estimated fractional-order economic system about Australia has four equilibrium points $(-0.246,0.499,0.523),(1.125,0.964,0.509),(-0.053,-0.470$, $-1.272)$ and $(-3.948,-2.578,0.352)$. The stability of the fixed points is analyzed in Table 3 . In Table 3, the unstable measures of each equilibrium points show that all of them are unstable and are saddle points. It suggests that the fractional economic system of US is unstable system. From simulation results about trajectory and time responses of each variable in Figure 5, the variables GDP, inflation, and unemployment 


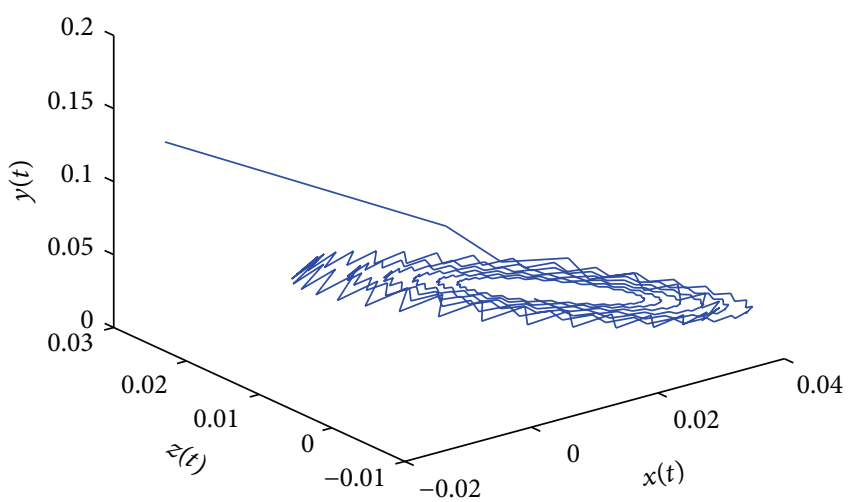

(a) Space trajectories

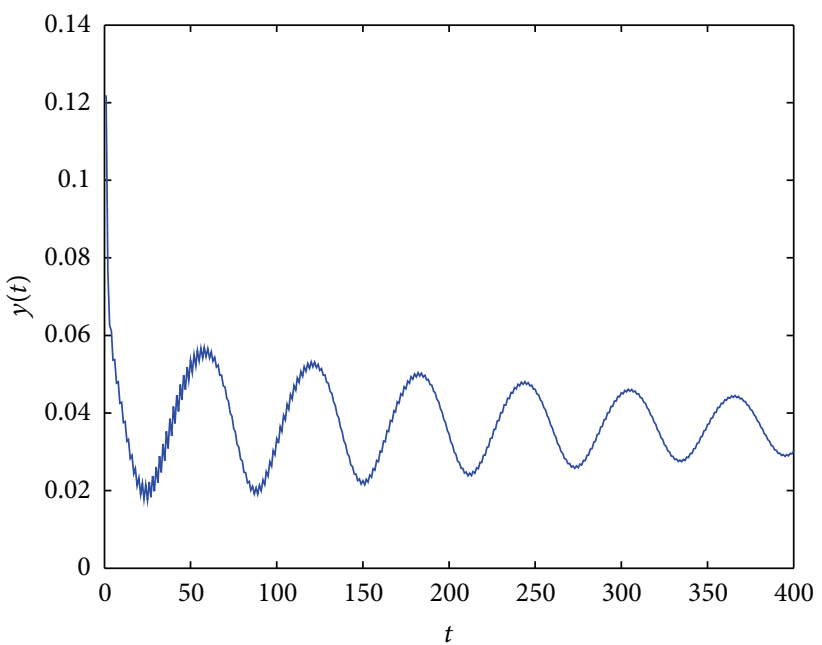

(c) $y(t)$ versus time

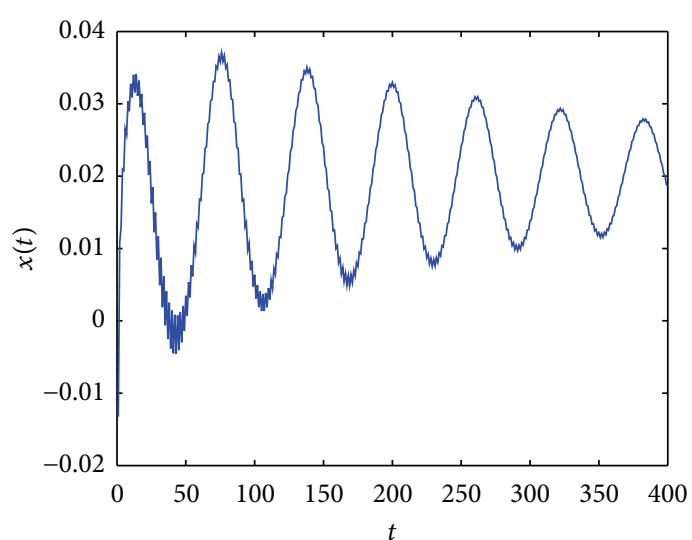

(b) $x(t)$ versus time

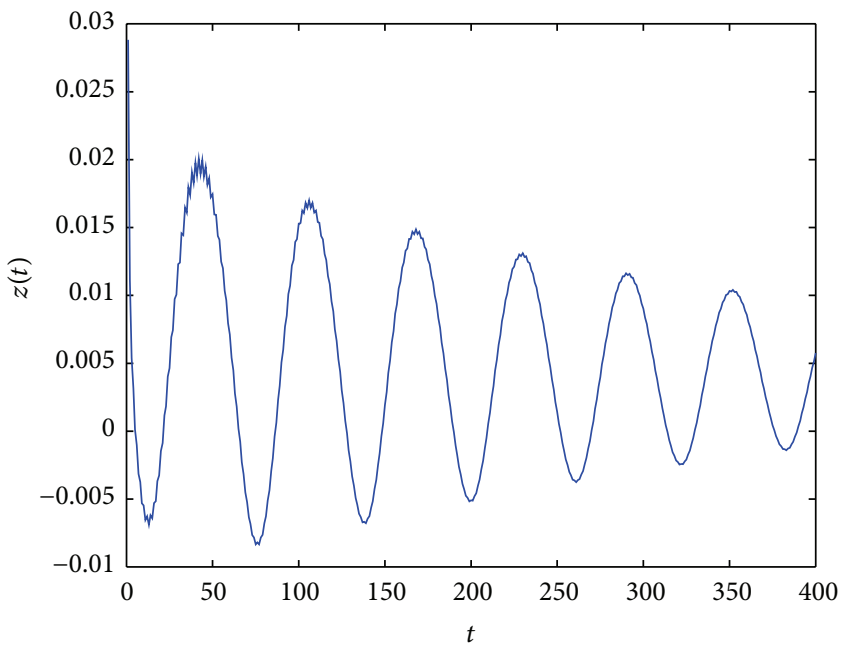

(d) $z(t)$ versus time

FIGURE 6: Space trajectory and the time responses of the estimated system about UK.

fluctuate irregularly. The simulation of fractional economic system also shows instability of system.

5.3. Fractional-Order Economic System about UK. The optimal order of fractional-order economic system about Australia is $(0.503,0.521,0.611)$ in Table 1 and analogously round to decile $(0.50,0.52,0.61)$. Obviously, $m=100$; then $\gamma(\pi / 2 m)=0.0157$. The estimated fractional-order economic system about Australia has six equilibrium points $(-7.396,-3.483,2.776),(2.214,1.402,0.570),(-2.511,1.331$, $-1.694), \quad(0.072,0.074,0.014), \quad(0.364,0.381,0.097)$, and $(-4.748,-3.316,-6.044)$. The stability of the fixed points is analyzed in Table 4 . Table 4 shows the results about stability analysis of fractional economic at six fixed points. It suggests that there are three stable points and unstable points in fractional economic system about UK. Simulation results for estimated economic system are shown in Figure 6 and show that dynamic behaviors of three variables are unstable and fluctuate with width decreasing and centre on some value. Combining the results about analysis of equilibrium points and simulation for system, the fractional economic system for UN is unstable for the initial period and tends to periodical fluctuations.

\section{Conclusions}

In this paper, we propose a novel methodology to construct and analyze macroeconomic system based on fractionalorder derivative that can depict the characteristic of memory in actual data. The methodology to analyze the economic system combine the merit of empirical methods and numerical analysis methods and offset the disadvantage of a single method (empirical analysis or numerical analysis). The application of the methodology is shown by using the US, Australia, and UK macroeconomic data to demonstrate its effectiveness and applicability.

\section{Conflict of Interests}

The authors declare that there is no conflict of interests regarding the publication of this paper. 


\section{Acknowledgment}

This research is supported by the Natural Science Foundation of China under Grant no. 71203241.

\section{References}

[1] F. Collard and H. Dellas, "Exchange rate systems and macroeconomic stability," Journal of Monetary Economics, vol. 49, no. 3, pp. 571-599, 2002.

[2] F. Milani, "Learning, monetary policy rules, and macroeconomic stability," Journal of Economic Dynamics and Control, vol. 32, no. 10, pp. 3148-3165, 2008.

[3] L. D. Mello and D. N. Moccero, "Monetary policy and macroeconomic stability in Latin America: the cases of Brazil, Chile, Colombia and Mexico," Journal of International Money and Finance, vol. 30, no. 1, pp. 229-245, 2011.

[4] W. Semmler, "A macroeconomic limit cycle with financial perturbations," Journal of Economic Behavior and Organization, vol. 8, no. 3, pp. 469-495, 1987.

[5] R. Franke, "Stable, unstable, and persistentcyclical behaviour in a keynes-wicksell monetary growth model," Oxford Economic Papers, vol. 44, no. 2, pp. 242-256, 1992.

[6] J.-H. Ma and Y.-S. Chen, "Study for the bifurcation topological structure and the global complicated character of a kind of nonlinear finance system (I)," Applied Mathematics and Mechanics, vol. 22, no. 11, pp. 1240-1251, 2001.

[7] J. Cai, "Hopf bifurcation in the IS-LM business cycle model with time delay," Electronic Journal of Differential Equations, vol. 2005, no. 15, pp. 1-6, 2005.

[8] T. Steinberger, "Imperfect financial contracting and macroeconomic stability," Journal of Financial Stability, vol. 1, no. 4, pp. 451-465, 2005.

[9] W.-C. Chen, "Nonlinear dynamics and chaos in a fractionalorder financial system," Chaos, Solitons and Fractals, vol. 36, no. 5, pp. 1305-1314, 2008.

[10] J. Ma and Q. Gao, "Stability and Hopf bifurcations in a business cycle model with delay," Applied Mathematics and Computation, vol. 215, no. 2, pp. 829-834, 2009.

[11] W.-Y. Chang, H.-F. Tsai, and J.-J. Chang, "Interest rate rules and macroeconomic stability with transaction costs," International Review of Economics and Finance, vol. 20, no. 4, pp. 744-749, 2011.

[12] W. Deng, "Short memory principle and a predictor-corrector approach for fractional differential equations," Journal of Computational and Applied Mathematics, vol. 206, no. 1, pp. 174-188, 2007.

[13] Z. Wang, X. Huang, and G. Shi, "Analysis of nonlinear dynamics and chaos in a fractional order financial system with time delay," Computers and Mathematics with Applications, vol. 62, no. 3, pp. 1531-1539, 2011.

[14] T. Skovrönek, I. Podlubny, and I. Petras, "Modeling of the nationaleconomies in state-space: a fractional calculus approach," EconomicModelling, vol. 29, no. 4, pp. 1322-1327, 2012.

[15] A. Kilbas, H. Srivastava, and J. Trujillo, Theory and Applications of Fractional Differential Equations, Elsevier, Amsterdam, The Netherlands, 2006.

[16] S. Ma, Y. Xu, and W. Yue, "Numerical solutions of a variableorder fractional financial system," Journal of Applied Mathematics, vol. 2012, Article ID 417942, 14 pages, 2012.
[17] I. Podlubny, Fractional Differential Equations, Academic Press, New York, NY, USA, 1999.

[18] I. Petras, "Stability of fractional-order systems with rational orders: a survy," An Fractional Calculus and Applied Analysis, vol. 3, no. 12, pp. 269-298, 2009.

[19] H. S. Najafi, A. R. Sheikhani, and A. Ansari, "Stability analysis of distributed order fractional differential equations," Abstract and Applied Analysis, vol. 2011, Article ID 175323, 12 pages, 2011.

[20] J. H. Holland, Adaptive in Natural and Artificial Systems, University of Michigan Press, Ann Arbor, Mich, USA, 1975.

[21] D. E. Goldberg, Genetic Algorithms in Search Optimization and Machine Learning, Addison Wesley, 1997.

[22] T. Back, Evolutionary Algorithms in Theory and Practice: Evolution Strategies, Evolutionary Programming and Genetic Algorithms, Oxford University Press, New York, NY, USA, 1996.

[23] A. D. Channon and R. I. Damper, "Towards the evolutionary emergence of increasingly complex advantageous behaviours," International Journal of Systems Science, vol. 31, no. 7, pp. 843$860,2000$. 


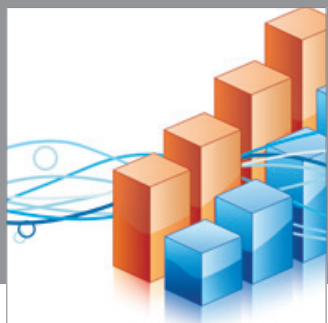

Advances in

Operations Research

mansans

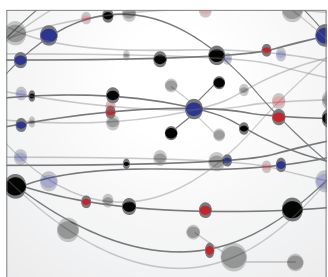

The Scientific World Journal
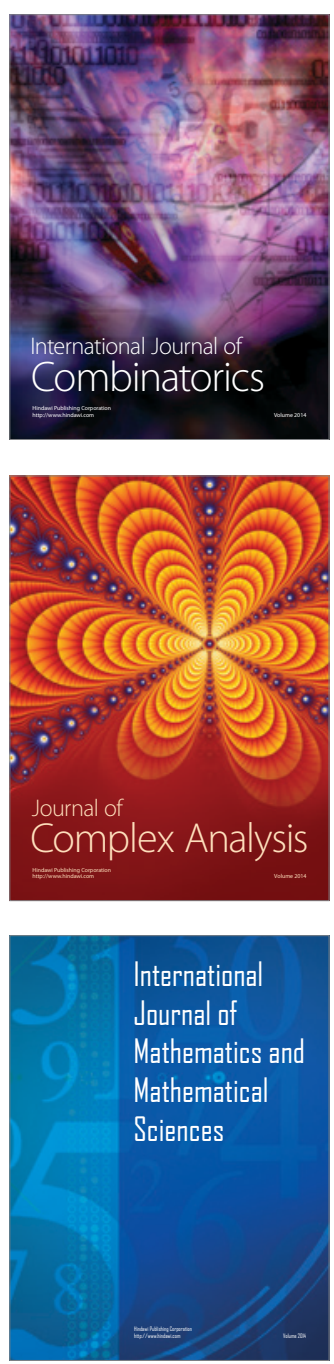
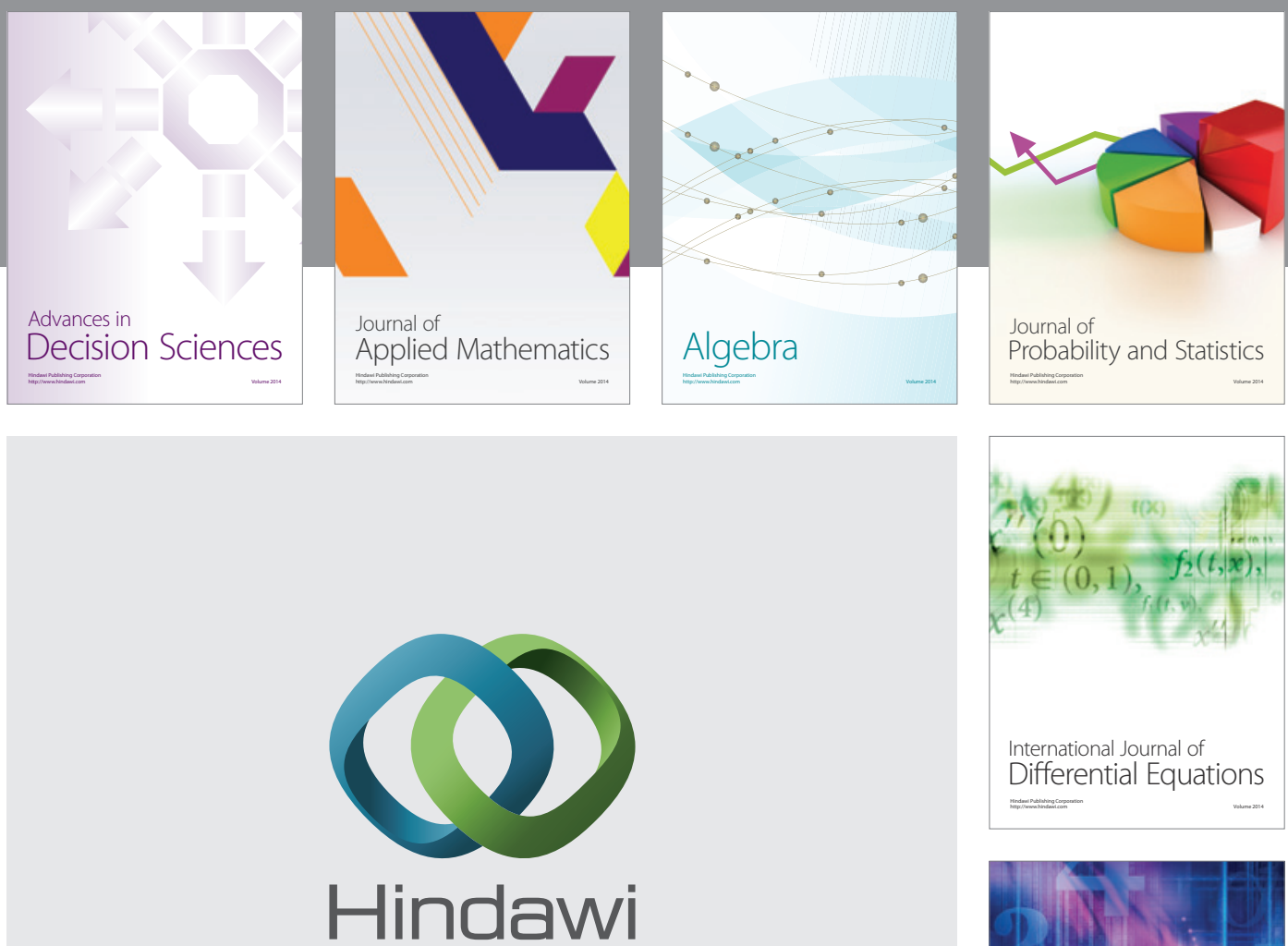

Submit your manuscripts at http://www.hindawi.com
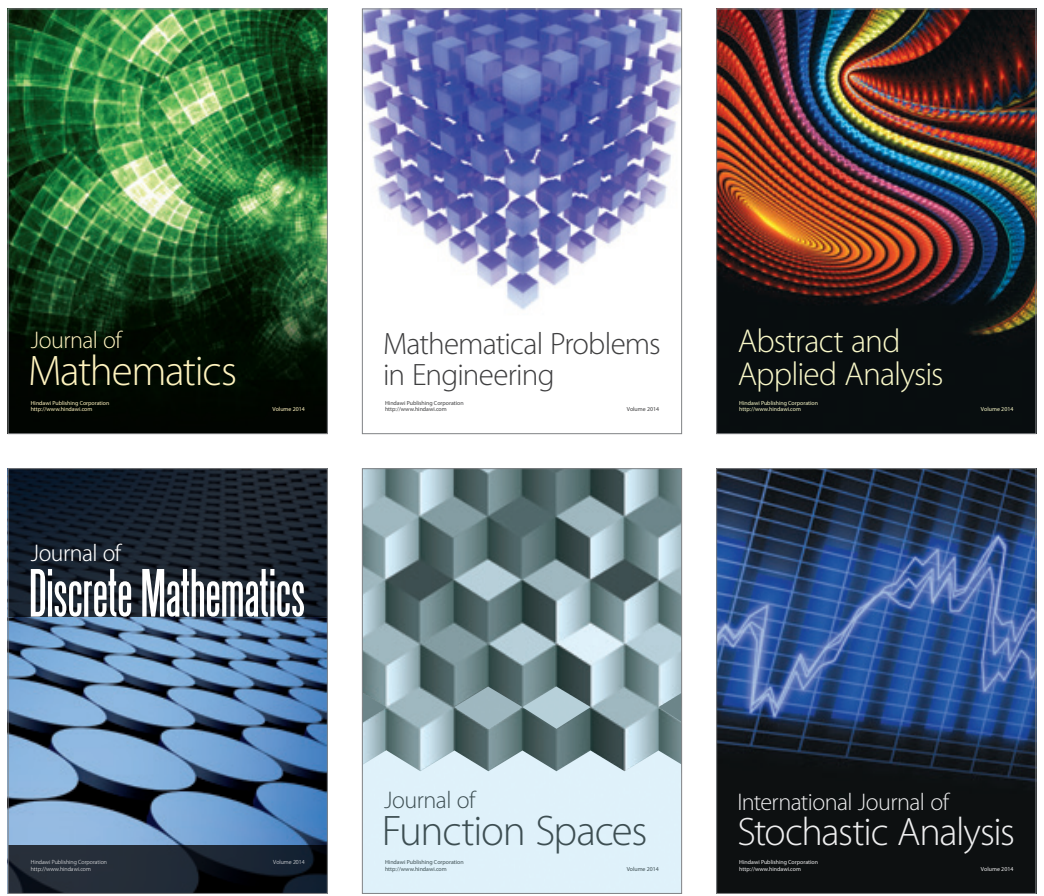

Journal of

Function Spaces

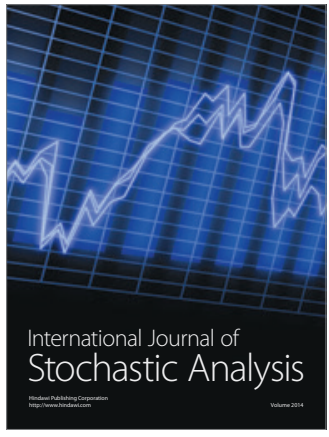

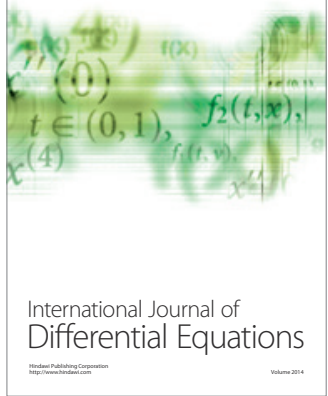
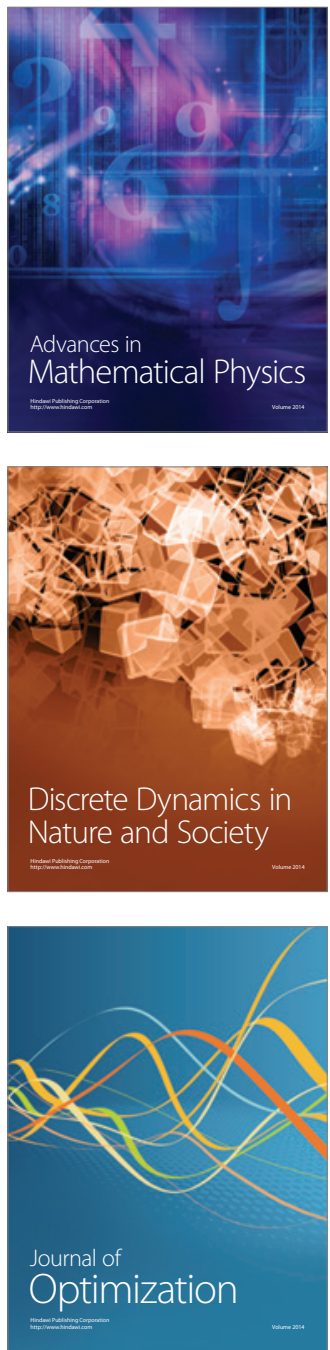